\title{
Comparison of action performances and outcome between winners and losers in young female silat tempur matches
}

\author{
Mohamad Nizam Mohamed SHAPIE ${ }^{* 1,2}$, Diyanna Athirah JAMSARI ${ }^{1}$, Afrina MOHD RAZI ${ }^{1}$, Jamiaton \\ KUSRIN $^{1}$, \& Wahidah TUMIJAN 1,3 \\ ${ }^{1}$ Faculty of Sports Science \& Recreation, Universiti Teknologi MARA (UiTM), Shah Alam, Selangor \\ (Malaysia) \\ 2 Seni Gayung Fatani Malaysia Association (PSGFM) (Malaysia) \\ ${ }^{3}$ Faculty of Sports Science \& Recreation, Universiti Teknologi MARA (UiTM), Seremban 3, Negeri \\ Sembilan (Malaysia)
}

8th IMACSSS International Conference Abstracts, Viseu (Portugal), October 10-12, 2019

Type: Oral communication

\begin{abstract}
Silat (a.k.a. gayung) tempur is a combat sports competition introduced to provide early preparation for the beginners to master the basic techniques of silat before they shift to silat olahraga (advanced level competition). The purpose of this study was to compare the performance of actions and outcome during action time between winners and losers in national silat tempur competition. The notational analysis focused on five different types of action categories in silat tempur; kick, punch, topple, block and catch. The action categories were divided into three outcomes; Hit Target (HT), Hit Elsewhere (HE) and Missing Opponent (MO). The researchers observed 19 female silat matches (each with three round games) aged 14 to 17-yearold. The observations were made through series of videos. Matched Paired $t$-test was used to analyse each action performances and outcome between winners and losers. Results showed that the winners performed more actions than the losers $(p<0.05)$. The winners frequently used more kicks to attack their opponents $(p$ $<0.05)$. However, there were similar performance between winners and losers in punch, block, topple and catch categories (all actions, $p>0.05$ ). The winners performed more successful actions (HT) than the losers $(p<0.05)$, particularly on kicks and blocks (both actions, $p<0.05)$. The losers significantly missed (M0) more catch actions than the winners $(p<0.05)$. The author concluded that kicks were the main actions that both exponents used during silat matches, with the winners performing more successful actions than the losers.
\end{abstract}

Keywords: Malay sports; martial arts; combat sports; gayung; performance analysis; competition.

\section{Introduction}

The word silat means a kind of sport or game, which consists of quick movements in attacking and defending (Anuar, 1993). It is characteristic of silat its step patterns, that makes it different from other combat sports (Shapie et al. 2018c). There are two types of sparring competition in silat; silat olahraga (Shapie \& Elias, 2015a) and silat tempur (Shapie \& Elias, 2014). Silat olahraga is a combat sport that consists of rapid movements in attacking and defensive activities (Shapie et al., 2013) in order to prevent the attacker from causing any harm towards oneself (Shapie et al., 2015a). Tempur means combat, sparring or battle between exponents (Shapie et al., 2019). This combative sport focuses on young exponents, particularly beginners (Shapie et al., 2018a). The main agenda of this sport is to improve combative techniques performed by young silat exponents in competition (Shapie et al., 2019). It is a platform to establish and develop young athletes who have courage and are technically and tactically skilled in combat (Shapie, Elias 2014).

Notational analysis in combat sports can be a useful tool to help coaches and athletes to improve their technical and tactical skills and prepare for competition (Shapie et al., 2008; Shapie et al., 2018). Studies in this regard include silat olahraga (Shapie et al., 2018a; Shapie et al., 2013), judo (Nagai et al., 2019), taekwondo (Suppiah et al., 2017) or karate (Tabben et al., 2019). Shapie et

*Email: nizam7907@uitm.edu.my

(C) 2019 Universidad de León. www.unileon.es 
al. (2013) used notational analysis to identify and describe the actions performed during the fight time of silat matches, which can assist in developing of specific training programmes. To date there is no research that specifically describes the actions involved in silat tempur that contribute to the winning the match. Athletes may exhibit a unique performance signature which can be used to predict future performance from past observation (Franks et al., 1998; Hughes and Potter, 2001). Thus, this information can be useful in developing strategies for the better development of silat competitors.

\section{Objectives}

The purpose of this study was to compare the actions and actions outcomes performed by winners and losers of female national-level silat tempur matches.

\section{Methodology}

Nineteen publicly recorded matches of young female exponents (aged 14 to 17 year-old) from National Silat Tempur Competition 2019 were analysed for this study. All eight categories from class A (40 - $45 \mathrm{~kg}$ ) to free class (75 kg above) were included. The videos were repeated and played in slow motion to accurately identify the actions or skills performed by athletes. Five categories of common silat techniques were differentiated: punch, kick, block, catch and topple (Shapie et al., 2013). The action outcome was categorised in three levels: Hit Target (HT), Hit Elsewhere (HE) and Miss Opponent (MO). All the raw data collected from all the matches was transferred to Statistical Package for Social Science (SPSS) version 21.0 for analysis. Matched paired $t$-tests were used to compare differences between winners (W) and losers (L). Significance level was set at $(p<0.05)$.

\section{Results}

Winners $(M=65.21 \pm 24.47)$ performed more actions than losers $(M=55.58 \pm 19.91)$ for total actions $(p<0.05)$. There were no significant differences on total punch, block, catch and topple (all, $p>0.05$ ) between winners and losers except for kick (W, $M=35.47 \pm 13.18$; L, $M=27.79 \pm$ $12.39, p<0.05)$.

The action outcomes showed no significant difference between winners and loser on HE and MO (both, $p>0.05$ ) except for HT (W, $M=38.58 \pm 16.45$; L, $M=26.00 \pm 15.07, p<0.05$ ). The winners performed more actions of HT on kick (W, $M=16.84 \pm 4.45$; L, $M=8.42 \pm 3.92, p<0.05$ ) and block actions $(\mathrm{W}, M=2.37 \pm 3.80 ; \mathrm{L}, M=0.79 \pm 1.03, p<0.05)$ compared to the losers. However, the losers significantly performed more MO than the winners on catch action (L, $M=0.74$ $\pm 1.15 ; \mathrm{W}, M=0.21 \pm 0.54, p=0.021$ ).

\section{Discussion}

The purpose of current study was to analyse the differences in actions and actions outcomes performed by winners and losers of female national-level silat tempur matches. We found that the total actions performed by the winners was significantly higher than those performed by the losers. This can be explained due to the nature of winning and losing in silat tempur, which is based on the total points scored by the athletes in a match. In silat, any legal/clear points (HT) with a punch (1 point), kick ( 2 points) or topple down (3 points) will help the athlete to increase his/her score (Anuar, 1992). Shapie et al. (2018a) reported that the winners from 19 matches in international silat matches performed more actions than the losers. Secondly, this study showed that the most frequent successful action performed by the winners was kick. This indicates that this skill is of upmost importance in silat tempur matches, many time deciding who wins or loses the match. The winners also performed more numbers of blocks than the losers. Shapie et al. (2013) point out that blocking is the common action in silat for defensive actions, particularly blocking kicks delivered by the opponent. The winners performed more successful blocks than losers, avoiding their rivals score points. Finally, losers performed more MO catch actions, therefore them failing to properly catch the attacks from the winners and missing the opportunity to topple down or hitting the opponent. Although our data was based on current competition, more studies are necessary to get 
more evidence on the actions performed by silat tempur athletes in competition, also including male competition and more complex analyses at the technical and tactical levels.

\section{Conclusion}

The winners performed more actions, particularly kicks, compared to the losers. The ability to kick accurately was the major contribution in gaining points, whilst blocking the attacks successfully prevented the opponent from scoring points. The details analysis give insight on how young female athletes perform in silat tempur competition and can be useful for coaches to improve their athletes' training processes (Shapie \& Elias, 2015b; Shapie et al., 2014) and transfer these processes to competition (Shapie et al., 2018b).

\section{Acknowledgment}

We would like to thank Akademi Silat Malaysia and Pertubuhan Seni Gayung Fatani Malaysia for volunteering for the study especially to Grandmaster Aminuddin Anuar his support in this study. Special thanks to Institute of Research Management and Innovation, Universiti Teknologi MARA for the financial support for this research (600-IRMI/DANA 5/3/LESTARI [0142/2016]).

\section{References}

Anuar, A. (1993). Silat olahraga. The art, technique and regulations (2nd edn.). Kuala Lumpur: Dewan Bahasa dan Pustaka.

Franks, I. M., Hodges, N., \& McGarry, T. (1998). Observation and instruction: Questions for established coaching practice. In M. Hughes \& F. Tavares (Eds.), Notational analysis of sport IV: Proceedings of the IV world congress of notational analysis of sport (pp. 13-22). Porto, Portugal: University of Porto.

Nagai, S., Takito, M. Y., Calmet, M., Pierantozzi, E., \& Franchini, E. (2019). Successful transition to groundwork combat during junior and senior judo world championships. International Journal of Performance Analysis in Sport, 19(2), 206-215. doi: $10.1080 / 24748668.2019 .1585739$

Shapie M.N.M., \& Elias M.S. (2014). The Silat Tempur Model: A Comparison Review with Silat Olahraga Sport. Poster presented at the Kongres Warisan Melayu Sedunia 2014. Kuala Lumpur, Malaysia.

Shapie M.N.M., \& Elias M.S. (2015a). Silat Olahraga: The Malay Combat Sports. In R.M. Kalina (Ed.), Proceedings of the 1st World Congress on Health and Martial Arts in Interdisciplinary Approach (p. 212). Czestochowa, Warsaw, Poland: Archives of Budo.

Shapie M.N.M., \& Elias M.S. (2015b), Seni Silat Malaysia: The Malay Arts of Self-Defence. In R.M. Kalina (Ed.), Proceedings of the 1st World Congress on Health and Martial Arts in Interdisciplinary Approach (pp. 213). Czestochowa, Warsaw, Poland: Archives of Budo.

Shapie, M. N. M., Oliver, J., O'donoghue, P., \& Tong, R. (2013). Activity profile during action time in national silat competition. Journal of Combat Sports and Martial Arts, 4(1), 75-79. doi: $\underline{10.5604 / 20815735.1073630}$

Shapie, M.N.M., Oliver, J., O'Donoghue, P.G., \& Tong, R. (2014). Fitness characteristics of youth silat performers. Malaysian Journal of Sport Science and Recreation, 10(1), 40-53.

Shapie, M. N. M., Elias, M. S., Ismail, S., \& Hamid, N. A. (2015). Seni Silat Malaysia curriculum contribution to heritage and malay civilization. Paper presented at the International Conference of Malay Heritage and Civilization (ICOMHAC) 2015, Langkawi, Kedah, Malaysia.

Shapie, M. N. M., Ali Janah, N. A., Kusrin, J., Tumijan, W., \& Elias, M. S. (2018a). Activity profile between winners and losers in international silat olahraga matches. Journal of Physical Fitness, Medicine \& Treatments in Sports, 2(4), 1-4. doi: 10.19080/JPFMTS.2018.02.555592

Shapie M.N.M., Oliver J., O’Donoghue P.G., \& Tong R. (2018b), Effect of Circuit Training on Fighting Performance of Young Silat Athletes - A Case Study. Malaysian Journal of Movement, Health \& Exercise, 7(1), 27-41.

Shapie M. N. M., Nur Afiqah A. J., Kusrin J., Wahidah T., \& Elias M.S. (2018c). Silat Tempur: The Combat Sports for Children. In N. Sulaiman, S.I. Ismail \& R. Adnan (Eds.), Proceedings of the 3rd International Colloquium on Sports Science, Exercise, Engineering and Technology (pp. 151-158). Singapore: Springer Nature. 
Shapie, M. N. M., Wahidah, T., Kusrin, J., Elias, M.S., \& Abdullah, N.M. (2019). Silat Tempur: An Overview of the Children's Combat Sports. Ido Movement for Culture. Journal of Martial Arts Anthropology, 19(1s), 55-61. doi: 10.14589/ido.19.1S.9

Suppiah, P., Joummy, A., Abdullah, M., Maliki, A., Musa, R., Mat-Rasid, S., \& Juahir, H. (2017). The strategy differences and movement pattern between medalist and non-medalist taekwondo youth athlete. Journal of Fundamental and Applied Sciences, 9(2S), 858- 868. Doi: 10.4314/jfas.v9i2s.61

Tabben, M., Conte, D., Haddad, M., \& Chamari, K. (2019). Technical and tactical discriminatory factors between winners and defeated elite karate athletes. International Journal of Sports Physiology and Performance, 14(5), 563-568. Doi: 10.1123/ijspp.2018-0478 